\title{
Quem são os Pedagogos Que ATUAM NAS INSTITUIÇÓES DE ENSINO PÚBLICO DA SRE DE Ouro Preto, Minas Gerais? O PERFIL E A FORMAÇÃO EM FOCO
}

\author{
Who are the Pedagogues that Work in the Public \\ education institutions of the SRE of Ouro Preto, \\ Minas Gerais? The Profile and fOCUS Training
}

\author{
Nilzilene Imaculada Lucindo \\ Doutoranda em Educação pelo Programa de Pós-Graduaçáo da Universida- \\ de Federal de Ouro Preto. Professora da Faculdade de Educaçáo da Univer- \\ sidade do Estado de Minas Gerais. Minas Gerais - MG - Brasil \\ https://orcid.org/0000-0003-2766-8951 \\ nilzilenelucindo@yahoo.com.br
}

\begin{abstract}
Regina Magna Bonifácio de Araújo Doutorado em Educaçáo pela Universidade Estadual de Campinas. Professora e pesquisadora no Programa de Pós-graduação em Educação e no Mestrado Profissional em Ensino de Ciências da Universidade Federal de Ouro Preto. Minas Gerais - MG - Brasil https://orcid.org/0000-0001-7289-5876 regina.magna@hotmail.com
\end{abstract}

Resumo: Este artigo apresenta os resultados de uma pesquisa de Mestrado cujo objetivo foi conhecer quem são os pedagogos que atuam nas instituiçóes de ensino público da Superintendência Regional de Ensino de Ouro Preto / MG. O estudo, de abordagem qualitativa, fez uso de análise documental, questionário e entrevista para coletar os dados, com posterior tratamento das entrevistas pela análise de conteúdo. Os resultados indicaram que esses pedagogos têm na base de sua formação o curso de Magistério e são os especialistas de educação formados na vigência do Parecer CFE no 252/69, quando o curso de Pedagogia estava estruturado por habilitaçôes. Ao analisarmos a formação inicial que receberam identificamos que ela foi bem teórica, com pouco incentivo à pesquisa, e que o contato com o campo profissional se deu essencialmente a partir do estágio. A formaçáo continuada da qual participam hoje não é específica para esses profissionais que atuam na coordenação pedagógica, demonstrando uma lacuna nessa formação.

Palavras-Chave: Curso de Pedagogia. Formação do Pedagogo. Pedagogo. 
Abstract: This article presents the results of a master 's research whose objective was to know who are the pedagogues that work in the institutions of public education of the Regional Superintendence of Education of Ouro Preto / MG. The study, using a qualitative approach, used documentary analysis, a questionnaire and an interview to collect the data, with subsequent treatment of interviews by content analysis. The results indicated that these pedagogues are based on their training in Teaching Magisterium and are the education specialists trained in the CFE Opinion no. 252/69, when the Pedagogy course was structured by qualifications. When we analyzed the initial training they received, we identified that it was very theoretical, with little incentive to research, and that the contact with the professional field was essentially from the stage. The continuing education in which they participate today is not specific to those professionals who work in pedagogical coordination, showing a gap in this formation.

Keywords: Education Course. Formation of the Educator. Educator.

\section{Introdução}

O curso de Pedagogia foi instituído há 80 anos e ainda hoje a formação do pedagogo se revela um desafio. Ao olharmos para a história desse curso observamos que ele foi se constituindo repleto de questionamentos: questionava-se sua identidade e finalidade, o currículo proposto, a dicotomia entre bacharelado e licenciatura, a fragmentaçáo presente no curso ocasionada pela instituição das habilitações, a centralidade na docência ou na pedagogia, os reducionismos presentes em função da base estabelecida, a amplitude da formação oferecida, o perfil do profissional pedagogo formado e o campo de atuação dos egressos. Esses questionamentos contribuíram para intensificar as discussóes acerca do curso e para lhe impor alteraçóes.

Após sua criação, o curso de Pedagogia foi modificado pelos Pareceres do Conselho Federal de Educação (CFE) no 251/62 (BRASIL, 1963) e no 252/69 (BRASIL, 1969) e pela Resolução do Conselho Nacional de Educação (CNE) no 1/2006 (BRASIL, 2006). Essas alteraçôes acarretaram mudanças no perfil do egresso fazendo com que o profissional formado pelo curso de Pedagogia assumisse características distintas em consonância com a legislação vigente à sua época de formação. Embora não se trate de um curso novo, a cada modificação que o curso passa há necessidade de avaliar os reflexos da formação que vem sendo oferecida com base na legislação que o regula, pois se trata de um curso responsável pela formação dos professores que atuarão na Educação Infantil e nos 
anos iniciais do Ensino Fundamental, bem como daqueles profissionais que farão a gestão do sistema educacional brasileiro e em outros espaços e aspectos das práticas educativas.

Os dados que apresentamos contemplam os resultados de uma pesquisa de Mestrado desenvolvida no Programa de Pós-Graduação em Educação da Universidade Federal de Ouro Preto cujo objetivo geral foi conhecer quem são os pedagogos que atuam nas instituiçôes de ensino público da Superintendência Regional de Ensino de Ouro Preto ${ }^{1}$ (SRE$\mathrm{OP})$. Este artigo enfoca o perfil desses profissionais, como se constituiu sua formaçáo inicial e como ocorre a formação continuada no âmbito de sua atuação profissional.

A metodologia adotada na investigação, de abordagem qualitativa (BOGDAN; BIKLEN, 1994), privilegiou a análise documental e tomou por base os dispositivos legais que tratam do curso; pesquisa bibliográfica embasada em livros, artigos, dissertaçóes e teses que tratam da temática investigada; e pesquisa de campo que contou com a colaboração de pedagogos detentores de cargo efetivo e atuantes como coordenadores pedagógicos em instituiçóes de ensino público localizadas nos municípios que compóem a jurisdição da SRE-OP. Na coleta de dados foi utilizado um questionário para identificar o perfil e uma entrevista semiestruturada que procurou desvelar a formação inicial e continuada, dentre outras questôes. Para tratar os dados coletados em entrevistas utilizamos a técnica de análise de conteúdo, conforme proposta por Bardin (2011).

Visando fundamentar a formação do profissional de Pedagogia, na Introdução deste artigo tomamos como ponto de partida a trajetória histórica do curso de Pedagogia no Brasil, constituída a partir dos quatro marcos legais que o configuraram e dos estudos de autores que se debruçaram sobre a temática. Na seção seguinte apresentamos uma descrição do perfil dos protagonistas da investigação, recorrendo aos dados obtidos por meio do questionário. Posteriormente, embasados nas entrevistas dos sujeitos da pesquisa que relataram acerca de sua formação, contexto de trabalho e profissão, explicitamos as análises sobre sua formação inicial e continuada. Concluímos o texto apontando algumas consideraçóes, além de sintetizarmos as reflexóes elaboradas sobre os achados da pesquisa. 


\section{O curso de Pedagogia e a formação do pedagogo no contexto brasileiro}

Criado no Brasil em 1939 pelo Decreto-Lei 1.190/39 (BRASIL, 1939), o curso de Pedagogia surgiu como uma das cinco seçôes (Filosofia, Ciências, Letras, Pedagogia e Didática) que compunha a Faculdade Nacional de Filosofia. De acordo com Scheibe e Aguiar (1999), ele nasceu da preocupaçáo com a formação de professores para atuação no Ensino Normal. Pela organização a que estava submetido, formava em três anos o Bacharel em Pedagogia, profissional formado para atuar como Técnico/Especialista de Educação que, para se tornar professor do ensino secundário e das Escola Normal, necessitava frequentar um segundo curso, o de Didática, com duração de um ano - assim, lhe era conferido o diploma de Licenciado em Pedagogia. Para Silva (2011, p.142), tratava-se de dois cursos distintos: "[...] o 'curso de Pedagogia', como bacharelado, e o 'curso de didática', como licenciatura a ser oferecido após aquele [...]" Mediante a disposição proposta no currículo, "o bacharelado permaneceu, portanto, como base da formação do Pedagogo." (SCHEIBE; DURLI, 2011, p.88)

O curso de Pedagogia manteve-se de acordo com sua configuração inicial por vinte e três anos, tendo sua primeira alteração proposta por meio do Parecer CFE no 251/62 (BRASIL, 1963), que alterou apenas o currículo estabelecendo uma base comum e outra diversificada e a duração do curso para quatro anos, tanto para o Bacharelado quanto para a Licenciatura. O currículo mínimo foi fixado em sete matérias (Psicologia da Educação, Sociologia Geral e da Educação, História da Educação, Filosofia da Educação, Administração Escolar e duas matérias a serem escolhidas pela IES), mas as disciplinas de Didática e Prática de Ensino eram obrigatórias para a Licenciatura. Para Silva (2011), a Licenciatura deixa de se configurar como um curso de didática e, ao se propor um currículo mínimo, no qual é possível optar por duas disciplinas e no elenco dessas opcionais configuram disciplinas mais voltadas para as atividades profissionais, "pode-se observar que já se verificava aqui a transição para a introdução da segunda versão - a do especialista.” (SILVA, 2011, p.145). No mesmo ano da publicação do Parecer CFE no 251/62 foi aprovado o Parecer CFE no 292 em 14/11/62 que estabeleceu 
as matérias pedagógicas do currículo mínimo dos cursos que habilitam para a docência.

Em 1968 foi aprovada a Lei no 5540/68 (BRASIL, 1968), também conhecida como 'lei da reforma universitária', a qual pode ser considerada um dos dispositivos que deu origem ao Parecer do CFE no 252/69 (BRASIL, 1969), que introduziu uma segunda modificação no curso. Esse Parecer manteve a formação de professores para atuar no Ensino Normal e, ao lado dela da habilitação já existente, instituiu as habilitaçôes de supervisão, orientação, administração e inspeção escolar, fato que levou a identidade do pedagogo ser a do especialista. O currículo do curso passou a ter uma parte composta pelos fundamentos da educação comum a todas as modalidades e uma específica em função da habilitação adquirida; além disso, a experiência de Magistério passou a ser exigida para as habilitações de Orientação Educacional, Administração e Supervisão Escolar, e Didática tornou-se uma disciplina obrigatória. Mediante a instituição desse Parecer o bacharelado foi extinto e o curso passou a conferir o título único de Licenciado em Pedagogia. Sob a égide desse Parecer, a formaçáo dos pedagogos correspondia às exigências do mercado de trabalho daquele período (BRASIL, 1969), o qual se embasava nos princípios da racionalidade técnica, eficiência e produtividade (SILVA, 2006), buscando atender ao modo de produção capitalista (PINHEIRO; ROMANOWSKI, 2010), dado que, conforme afirmou Libâneo (2010, p.46), vigorou a ideia de "formar o especialista no professor."

Lima (2004) destaca que na vigência dos pareceres anteriores a fragmentação do curso se apresentava na separação em bacharelado e licenciatura e, na vigência do Parecer CFE no 252/69, o caráter fragmentado se deu em função da instituição das habilitações, o que, na visão de Libâneo e Pimenta (2011, p.22), foi uma forma de definir o "exercício profissional do pedagogo não-docente." Conforme ressaltam esses autores, o Parecer CFE no 252/69 foi o que melhor determinou a natureza do curso de Pedagogia. Contudo, o cenário estabelecido na vigência desse parecer e que repercutiu na escola, separando o trabalho/formaçáo do professor e do especialista e a teoria da prática, desencadeou, para Libâneo (2007), um movimento em prol de um curso voltado para a formação de professores e o fim das habilitaçôes. 
Após a aprovação da Lei de Diretrizes e Bases da Educação (LDB) no 9.394/96 (BRASIL, 1996), foi iniciado, em 1997, um processo de reforma curricular e elaboração de diretrizes curriculares para os cursos de graduação. Depois de anos de debate, as diretrizes do curso de Pedagogia foram instituídas pela Resolução CNE no 01/2006, aprovada em 15 de maio do mesmo ano. Assim se deu a terceira modificação no curso que passou a ter a docência como base da formação do pedagogo e foi definido como uma licenciatura destinada

à formação de professores para exercer funçôes de magistério na Educação Infantil e nos anos iniciais do Ensino Fundamental, nos cursos de Ensino Médio, na modalidade Normal, de Educação Profissional na área de serviços e apoio escolar e em outras áreas nas quais sejam previstos conhecimentos pedagógicos.

Parágrafo único. As atividades docentes também compreendem participação na organização e gestão de sistemas e instituiçóes de ensino, englobando:

I - planejamento, execução, coordenaçáa, acompanhamento e avaliação de tarefas próprias do setor da Educação;

II - planejamento, execução, coordenação, acompanhamento e avaliação de projetos e experiências educativas não-escolares; III - produção e difusão do conhecimento científico-tecnológico do campo educacional, em contextos escolares e não-escolares. (BRASIL, 2006, p.2)

De acordo com Scheibe e Durli (2011), o conceito de docência implícito nas diretrizes engloba as funçôes de professor, gestor e pesquisador, o que também foi reconhecido por Evangelista e Triches (2008), as quais ainda destacaram a hegemonia da docência. Embora o curso apresente a docência como base da formação do pedagogo, o estudo da Pedagogia não pode ser relegado a um segundo plano, justamente por possuir uma dimensão que está além da docência. Argumentando sobre o reducionismo da pedagogia à docência, Libâneo e Pimenta (2011, p.33) justificam que

[...] a identificação do pedagogo com o docente incorre num equívoco lógico conceitual. A pedagogia é uma reflexão teórica 
baseada nas práticas educativas e sobre elas. Investiga os objetivos sociopolíticos e os meios organizacionais e metodológicos de viabilizar os processos formativos em contextos socioculturais específicos. Todo educador sabe, hoje, que as práticas educativas ocorrem em muitos lugares, em muitas instâncias formais, não-formais, informais. Elas acontecem nas famílias, nos locais de trabalho, na cidade e na rua, nos meios de comunicação e, também, nas escolas. Não é possível mais afirmar que o trabalho pedagógico se reduz ao trabalho docente nas escolas. A ação pedagógica não se resume a açôes docentes, de modo que, se todo trabalho docente é trabalho pedagógico, nem todo trabalho pedagógico é trabalho docente.

Para Libâneo (2001), é inconcebível restringir o trabalho do pedagogo ao trabalho docente, uma vez que o campo de atuação do profissional de Pedagogia não está circunscrito à sala de aula. Segundo este autor, o pedagogo possui um campo de trabalho que extrapola o âmbito escolar, pois há outros espaços além da escola que desenvolvem práticas educativas. Ele entende que o pedagogo é o

profissional que atua em várias instâncias da prática educativa, direta ou indiretamente ligadas à organização e aos processos de transmissão e assimilação de saberes e modos de ação, tendo em vista objetivos de formação humana previamente definidos em sua contextualização histórica. (LIBÂNEO, 2001, p.11)

Logo, ao reduzir o curso de Pedagogia à docência, esse estreitamento também se estendeu ao profissional, já que esse ficará restrito a ensinar na Educação Infantil e nos anos iniciais do Ensino Fundamental. Ao estabelecer a docência como a base do curso e abrir um leque amplo de formação, as diretrizes evidenciam, simultaneamente, a ênfase e a amplitude da formação oferecida. Resta saber se, de fato, o currículo proposto tem garantido a formação do professor para atuar na Educação Infantil e nos anos iniciais do Ensino Fundamental, além da formaçáo do gestor.

Pesquisas desenvolvidas com vistas a verificar como tem sido realizada a formação no curso de Pedagogia com base no último marco 
legal apresentam alguns indícios. Marin (2014, p.7), ao analisar o conteúdo dessa Resolução, adverte sobre "a possibilidade de encontrarmos, aqui, os mesmos princípios da grande mudança feita em 1969, abrindo várias possibilidades de formação em um único curso." A diversidade de formação profissional é uma preocupação para Leite e Lima (2010) devido ao locus onde a formação é realizada, já que pode se tratar de uma instituição descomprometida com a formação docente e ofertar todas as modalidades formativas dentro de uma carga horária insuficiente para contemplar todas elas. Nunes e Araújo (2014) concluíram em sua pesquisa que o curso privilegia a formação docente para os anos iniciais do Ensino Fundamental, tal qual apontou Pinheiro e Romanowski (2010), dados que demonstram a existência de lacunas na formaçáo do gestor e do professor de Educação Infantil.

Ao analisarem o projeto político pedagógico do curso de Pedagogia de três instituições da região Sudeste, construídos a partir das diretrizes de 2006, Albuquerque, Haas e Araújo (2013, p.112) destacam que "os perfis do pedagogo nos três projetos pedagógicos atendem às diretrizes, mas cada instituição fez uma opção do quanto investir na formação do professor e do gestor, diminuindo o espaço deste último.” No entendimento de Evangelista e Triches (2008, p.6), “[...] o curso é uma licenciatura que formará docentes para atuarem na Educação Infantil - EI - e anos iniciais do Ensino Fundamental - AIEF. Enfatize-se que essas duas modalidades serão de oferta obrigatória para as instituiçóes de ensino [...]" Como apontam os dados desse estudo, as lacunas existentes na formação inicial estão expressas e precisam ser repensadas. Talvez daqui a alguns anos, com base na divulgação de novas pesquisas, se torne mais explícita a necessidade de institucionalizar um curso voltado para a formação do professor e outro específico para a formação do pedagogo - especialista tal como propóem Libâneo (2010) e Albuquerque, Haas e Araújo (2013), e defendem Franco, Libâneo e Pimenta (2011). Ou ainda, como advoga Marin (2014), um curso denso voltado para a formação dos professores de séries iniciais e outro específico para o docente que atuará na Educação Infantil, pois "cada profissional desses pede uma formação diferenciada.” (LIBÂNEO, 2011, p. 65) 


\section{Os pedagogos que atuam nas instituiçóes de ensino público da SRE-OP}

\section{$\mathrm{O}$ perfil desses profissionais}

A amostra foi composta de 14 mulheres e 1 homem, totalizando 15 pedagogos que concluíram a graduação em Pedagogia entre 1983 e 2010, na vigência do Parecer no 252/69 e obtiveram o título de Licenciado em Pedagogia e as habilitaçóes que eram proporcionadas pelo curso. A Supervisão Pedagógica foi a habilitação mais cursada pelos entrevistados, dado que se aproxima da pesquisa de Somacal (2010), que ao tratar do perfil de seus entrevistados identificou que as habilitaçôes mais cursadas eram Orientação Educacional e Supervisão Escolar. A segunda habilitação mais cursada pelos pedagogos que atuam na jurisdição da SRE-OP foi o Magistério das Matérias Pedagógicas, que pode estar relacionado com o entendimento exposto por Valnir Chagas de que todo portador do diploma de Pedagogia, em princípio, é professor do Ensino Normal. (BRASIL, 1969)

Em relação ao gênero, os dados demonstram que o Magistério ainda é uma profissão tipicamente feminina. Carvalho (1996) registra que no Brasil, desde os anos 20, já existe essa tendência de a mulher ocupar o cargo de professora primária e, nos anos 90, tomando por base o estado de São Paulo, a autora registra que há uma intensificação da presença feminina na docência das séries iniciais para as séries finais do $1^{\circ}$ grau, para $o$ $2^{\circ}$ grau e nos cargos de especialista. O estudo da Organização das Naçóes Unidas para Educação, Ciência e Cultura (UNESCO, 2004) demonstrou que no Brasil $81,3 \%$ dos docentes são mulheres e $18,6 \%$ são homens. A pesquisa de Gatti e Barretto (2009, p.162) evidencia que "as mulheres constituem igualmente a maioria absoluta dos estudantes de Pedagogia." Apesar de o 'ser professora' constituir uma opção para as mulheres, o sujeito masculino que compóe a amostra ingressou no curso com o desejo de ser professor, desejo que se aproxima da opçáo de muitos outros que escolhem a Licenciatura, como explicitaram Gatti e Barretto. (2009)

As pedagogas e o pedagogo que compuseram nossa amostra atuam em escolas públicas nos municípios mineiros de Itabirito, Mariana e Ouro Preto. A amostra não contemplou profissionais de Acaiaca e Diogo 
de Vasconcelos, visto que, dos três sujeitos identificados na rede estadual em Acaiaca, dois não se interessaram em participar e um não possuía vínculo efetivo. Em Diogo de Vasconcelos, dos quatro sujeitos identificados nas duas redes todos são licenciados em outras áreas e com Pós-Graduação em Supervisão Escolar, demonstrando a situação que é estabelecida pelo artigo 64 da LDB no 9394/96. Esse achado também demonstra que os cargos de gestão (coordenação/supervisão pedagógica, direção de unidade escolar) deixam de ser exclusividade do profissional formado no curso de Pedagogia, já que licenciados em outras áreas também poderão ocupá-los.

Cinco pedagogos atuam na rede estadual e dez na rede municipal de ensino, contudo, eles já atuaram em outras redes e órgãos educacionais como a rede particular (quatro) e em secretarias municipais (três), evidenciando assim a experiência desses sujeitos em outros equipamentos de ensino. A Tabela 1 apresenta o nível de ensino em que os profissionais estão atuando.

\section{Tabela 1: Nível de ensino em que o pedagogo atua}

Sujeitos

Frequência

Educação Infantil

1

Ensino Fundamental - $1^{\circ}$ ao $5^{\circ}$ ano

Ensino Fundamental - $6^{\circ}$ ao $9^{\circ}$ ano

Ensino Médio

Educação Profissional

Educação Infantil e Ensino Fundamental - $1^{\circ}$ ao $5^{\circ}$ ano

Educação Infantil e Ensino Fundamental - $1^{\circ}$ ao $9^{\circ}$ ano

Ensino Fundamental $-1^{\circ}$ ao $5^{\circ}$ ano $/ 6^{\circ}$ ano ao $9^{\circ}$ ano

Ensino Fundamental - $6^{\circ}$ ao $9^{\circ}$ ano / Educação de Jovens e Adultos

Ensino Fundamental - $1^{\circ}$ ao $5^{\circ}$ ano / Educaçáo Profissional

Total

Fonte: Elaboração própria a partir de levantamento realizado com os pedagogos.

Ainda que todos tenham cursado Pedagogia, os cargos ocupados possuem nomenclaturas distintas estabelecidas pelo curso na vigência do Parecer no 252/69 ou pela rede de ensino em que atuam: oito são supervi- 
sores pedagógicos; dois são orientadores educacionais e cinco, pedagogos. Esse dado explicita que, na contemporaneidade, ainda vivemos com uma multiplicidade de denominaçôes atribuídas aos profissionais formados pelo curso de Pedagogia. São diversos os concursos públicos para a atuação do pedagogo que abrem vagas com diferentes especificaçôes: pedagogo, coordenador pedagógico, especialista de educação, gestor educacional, assistente técnico-pedagógico etc. Hoje, três profissionais atuam na função de diretor de escola; um na coordenaçãa dos supervisores pedagógicos da rede municipal e outro em duas funçōes: supervisor e inspetor.

A condição desse último profissional pode ser justificada em função da nomenclatura do cargo - pedagogo. Embora se trate de um profissional formado na vigência do Parecer no 252/69, sua atuação se dá no contexto da Resolução CNE/CP no 01/2006, segundo a qual o pedagogo assume, em um único cargo, todas as habilitaçôes propostas para o Especialista de Educação. Todavia, cabe um questionamento sobre a ênfase que se dá ao trabalho dele: está focado no processo pedagógico, no administrativo ou há uma divisão? A questão também pode ser justificada em função da organização estabelecida pela rede de ensino em Minas Gerais, já que o cargo de Inspetor Escolar pertence à rede estadual e a supervisão das instituiçóes de ensino, vincula-se às demais redes, sob a tutela do Estado de Minas Gerais. Nesse sentido, a instituição onde esse sujeito é lotado buscou uma forma de adequar-se às demandas de sua própria rede, incluindo aí a possibilidade de se ter um profissional 'polivalente', sendo desnecessário contratar outro profissional para desenvolver a segunda função.

A situação aqui encontrada se assemelha à relatada por Somacal (2010) em estudo sobre quem é o professor-pedagogo, nova configuração estabelecida para profissionais das escolas estaduais do Paraná após serem extintas as profissóes de Orientador Educacional e Supervisor de Ensino. Ao ser admitido como professor-pedagogo, o profissional assume as duas funçôes que foram extintas e agora estão vinculadas em um só cargo. Dessa forma, as funções exercidas referem-se a docência, suporte pedagógico, direção, coordenação, assessoramento, supervisão, orientação, planejamento e pesquisa. De acordo com Somacal (2010, p. 90), os entrevistados "percebem-se como profissionais, que possuem amplas funçóes, havendo uma 'multifuncionalidade', estas variando entre funçóes administrativas e pedagógicas." 
Onze participantes possuem habilitação em Magistério de $1^{\circ}$ grau para atuar de $1^{\mathrm{a}}$ a $4^{\mathrm{a}}$ série e um cursou o Magistério de $1^{\mathrm{o}}$ grau obtendo a habilitação para atuar com Educação Física da $1^{\mathrm{a}}$ à $6^{\mathrm{a}}$ série, conforme o artigo 30 da Lei no 5692/71 (BRASIL, 1971). Como indicam os dados de Gatti e Barretto (2009) e Braúna (2009), a pesquisa demonstra um perfil de entrevistados que, em sua maioria, antes de ingressar na Pedagogia, passou pelo curso de Magistério e já possui uma base teórica e prática de formação. Cenário que difere a partir dos anos 2000, segundo Braúna (2009), já que grande parte dos alunos que ingressam na Pedagogia não detêm o curso profissionalizante. Os entrevistados também possuem experiência nas funçóes de docente (12); diretor (6) e vice-diretor (1). O artigo 67 da LDB no 9394/96 (BRASIL, 1996) atesta que "a experiência docente é pré-requisito para o exercício profissional de quaisquer outras funçôes de magistério, nos termos das normas de cada sistema de ensino."

Quanto ao locus de conclusão da graduação, constatou-se que sete sujeitos concluíram seu curso em universidades, quatro em institutos de educação e os demais em faculdades isoladas. Ao discutirem sobre a organização acadêmica do ensino superior, Scheibe e Aguiar (1999) chamam a atenção para a distinção existente entre universidades de pesquisa e universidades de ensino e o lugar onde se desenvolverá a formação docente: o menos oneroso. Segundo as autoras, "estabeleceu-se como locus privilegiado para essa formação o nível mais baixo da hierarquia." (SCHEIBE; AGUIAR, 1999, p. 222) Para Diniz-Pereira (1999, p.113), nas instituiçóes de Ensino Superior, "em especial nas particulares e nas faculdades isoladas, é a racionalidade técnica que, igualmente, predomina nos programas de preparação de professores."

Pimenta (2014), ao tratar da formação oferecida pelos cursos de Pedagogia das instituiçóes de ensino público e privado de São Paulo, registra que a maioria é ofertada por instituiçóes privadas onde náo há exigência da pesquisa e os cursos são desenvolvidos com a carga horária mínima proposta pela legislação. No entendimento de Libâneo e Pimenta (2011, p.48), o pedagogo deve ser formado nas universidades, "que é o locus da produção social do conhecimento, da circulação da produção cultural em diferentes áreas do saber e do permanente exercício da crítica históricosocial." Concluímos que, certamente, o locus onde o pedagogo realizou seu curso irá influenciar a sua formação, principalmente em função de sua 
participação em atividades de ensino, pesquisa e extensão. Ademais, os relatos colhidos apresentam indícios de que os pedagogos que se formaram nas instituiçôes federais obtiveram uma formação mais abrangente.

Doze pedagogos possuem Especialização Lato Sensu e um deles também possui Mestrado Profissional em Pedagogia. A Tabela 2 apresenta as áreas cursadas na pós-graduação.

\section{Tabela 2: Área de Especialização}

\begin{tabular}{lc}
\hline Sujeitos & Frequência \\
\hline Pesquisa em Educação & 1 \\
Psicopedagogia & 4 \\
Planejamento Educacional & 1 \\
Formaçáo de Professores & 1 \\
Gestão Escolar e Psicopedagogia & 2 \\
Metodologia e Didática & 1 \\
Matérias Pedagógicas & 1 \\
Pedagogia Empresarial & 1 \\
Total & 12 \\
\hline
\end{tabular}

Fonte: Elaboração própria a partir de levantamento realizado com os pedagogos.

\section{Como se constituiu sua formaçáo inicial?}

Ao abordar a história da formação docente, Saviani (2005; 2009) registra que a preocupação acerca da formação dos professores é antiga, tendo sido preconizada por Comenius, pensador que viveu no século XVI e XVII. Em Didáctica Magna, Comenius propôe que a educação deve ser aplicada a todos, já que a capacidade de aprender é uma característica natural do homem e o homem só se torna homem se for educado. Para tanto, era primordial a construção de escolas nas mais variadas comunidades bem como a existência de pessoas dotadas da capacidade de ensinar, instruídas para tal (COMENIUS, 2011). Nesse sentido, podemos constatar, como mencionou Saviani (2005; 2009), a preocupação de Comenius acerca da formação do professor. 
Nos últimos anos, cresceu o número de ações públicas empreendidas no campo da formação de professores:

Na última década, a preocupaçáo com a formação de professores entrou na pauta mundial pela conjunção de dois movimentos: de um lado, pelas pressôes do mundo do trabalho, que se vem estruturando em novas condiçôes, num modelo informatizado e com o valor adquirido pelo conhecimento, de outro, com a constataçáo, pelos sistemas de governo, da extensão assumida pelos precários desempenhos escolares de grandes parcelas da população. (GATTI, 2008, p. 62)

Pode-se dizer que a instituição da LDB no 9394/96 corroborou com esse processo ao exigir, dentre outras questóes, que a formaçáo dos professores para atuar na Educaçáo Infantil e nas séries iniciais do Ensino Fundamental se faça em nível superior. Não obstante, a expansão da Educação a Distância também contribuiu para ampliar esse leque à medida que foram crescendo as ofertas de cursos nessa modalidade voltados para a formação inicial e continuada.

Também não se pode deixar de destacar que é amplamente difundi-

Era aula expositiva, tinha trabalhos de grupo, mas era assim, aula expositiva e trabalhos de grupo, estudo individual. O que eu me lembro era bem isso. Não tinha assim, tanto seminários, fóruns, oficinas. [...] Tinha trabalho individual e trabalho 
em grupo e aula expositiva. Náo tinha tantos recursos, a gente não tinha internet, nem tinha computador na época que eu estudava, nem sabia mexer, então assim, era o mais tradicional. (Pedagogo 1)

Expositiva e grupo. Expositiva e grupo. Era, estava naquela fase. É para você ver que tem 30 anos isso. Expositiva e grupo. Era muito grupo de estudo. Muito livro para ler. (Pedagogo 13)

Acerca das estratégias utilizadas pela maioria dos professores, Gatti e Barretto (2009, p. 174) salientam que as mais utilizadas são as aulas expositivas, sobressaindo-se também "a utilização de trabalhos em grupo na sala de aula", o que caracteriza o paradigma do ensino tradicional (PLACCO; SARMENTO, 2009). Nesta pesquisa, é evidenciada uma preocupação maior com as disciplinas teóricas, o que também já foi destacado no estudo de Cruz (2009) ao ressaltar as características do curso de Pedagogia. Embora os docentes fizessem uso de outras metodologias como debates, mesa-redonda, teatro, atividades com jogos, relatos de experiências, visitas técnicas, observação da prática e leitura dos clássicos da educaçáo, para oito entrevistados o curso se configurou como mais teórico e menos prático, o que constitui uma preocupação para Gatti e Barretto (2009) visto que aponta para o comprometimento da relação teoria x prática. De acordo com os pedagogos, as práticas estavam mais associadas às disciplinas de Metodologia.

É, na verdade, não foram tantas práticas. Eu acho que se for avaliar, teve mais formação teórica até do que prática. As práticas eram das metodologias. Então, por exemplo, na Metodologia da Matemática, então, a gente fazia muita aula prática. A gente montava jogos daquilo que a gente poderia fazer com o aluno. Simulava a aula. No assim, de Ciências, é que eram aulas mais práticas mesmo, de ir para o laboratório e de ver como é que poderia trabalhar aquilo nas séries iniciais. (Pedagogo 4)

Os dados revelaram que a teoria se sobressaiu em detrimento da prática, reiterando a conclusão apontada por Cruz (2012), Luz (2010) e Pimenta (1997). Pimenta (1997, p.11) registra que "tradicionalmente há 
uma cisão entre teoria e prática. E não tem sido raro professores e alunos clamarem por 'mais prática' (grifo da autora), uma vez que consideram os cursos 'muito teóricos' (grifo da autora)." Na percepção de Gatti e Barretto (2009, p. 175),

como, na prática docente da escola básica, os professores tendem a reproduzir mais as experiências provenientes da sua vivência como estudantes do que as teorias com as quais entram em contato, um dado preocupante é o extremo desequilíbrio, nos cursos de formação docente, entre as abundantes aulas expositivas e a absoluta escassez de aulas práticas em todos os cursos.

Para cinco entrevistados, o contato com a Educação Básica se deu apenas no estágio, conforme afirmou o Pedagogo 9: "Só no estágio e, às vezes, algum trabalho que a gente tinha que apresentar que era necessário estar indo para a escola." Libâneo e Pimenta (2011, p.45) concebem que "a docência constituiu um campo específico de intervenção profissional na prática social." Nesse sentido, entendemos que um profissional que está sendo formado, mas teve poucas chances de entrar em contato com seu futuro locus de atuação, de identificar e aprofundar o conhecimento sobre ção nela. Acreditamos que o contato com o campo profissional de atuação é condição sine qua non e propicia uma melhor apreensão da realidade justamente pela oportunidade que o graduando possui de vivenciar e participar das situações que são peculiares a esse campo.

Segundo os demais entrevistados, esse contato também foi viabilizado por meio de projetos de extensão, monitoria e de desenvolvimento de trabalhos extraclasses, além de poder considerar a vivência dos alunos oriundos do curso de Magistério e daqueles que já atuavam em sala de aula. Apenas três entrevistados que concluíram sua graduação em uma IES federal tiveram a oportunidade de se inserir no campo de atuação a partir da participação em atividades de extensão. Dessa forma, consideramos imprescindível possibilitar variadas formas de inserção dos licenciandos no seu campo de atuação profissional - quanto mais cedo isso ocorre, maior a possibilidade de compreensão do campo. $\mathrm{Na}$ atualidade, iniciativas como o Programa Institucional de Bolsa de Iniciação à Docência (PIBID) 
(BRASIL, 2010) propiciam o contato dos licenciandos com a escola básica. Gatti (2014) também destaca outras iniciativas em nível estadual como o Programa Especial de Formação de Professores da Zona Rural (Profir) do Acre, o Programa Bolsa Estágio Formação Docente do Espírito Santo e o Programa Bolsa Formação Escola Pública e Universidade, de São Paulo. Logo, observamos que há em execução outras formas de inserir os licenciandos no seu campo de atuação que extrapolam a forma convencional que se dava por meio do estágio.

Acerca do estágio, em seus depoimentos os pedagogos não explicitaram sua carga horária nem como se dava o acompanhamento do estágio por parte das instituiçóes formadoras. Treze entrevistados realizaram o estágio na área em que se tornaram especialistas, conforme era estabelecido pelo Parecer CFE no 252/69, exigência que, na compreensão de Silva (2006), se dá pelo fato de possibilitar ao portador desse título profissional uma vivência na especialidade na qual atuará. Seis pedagogos declararam que o estágio foi realizado ao final do curso e dois informaram que ele foi realizado desde o início. Segundo Pimenta e Lima (2012, p.45), "o estágio curricular é atividade teórica de conhecimento, fundamentação, diálogo e intervençáo na realidade [...]" Tradicionalmente, ele está estruturado em observação, participação e regência, todavia, afirma Pimenta (1997, p. 68) que "pelo simples fato de introduzir o aluno na escola para observar o seu funcionamento, não capacita o aluno para desvendar a complexidade desta." O estágio deve ser um espaço de questionamento e investigação, e realizá-lo em um curto espaço de tempo não favorece o preparo para o exercício da profissão.

Verificamos que o incentivo à pesquisa se deu apenas para seis entrevistados.

Então, contato com a pesquisa foi nesse Programa [de Alfabetização de Adultos] que eu tinha dois anos e meio com Professores Doutores que já me orientavam [...] E o tema era verificar a evoluçáo e as fases que o aluno passava no decorrer da alfabetização, verificar se era o mesmo processo que as crianças, entendeu? (Pedagogo 14)

Sete entrevistados disseram náo ter tido contato com a pesquisa e dois relataram que pesquisavam apenas para fazer os trabalhos propostos: 
Então eu acho que nesse ponto, do incentivo à pesquisa, de fazer a pesquisa eu acho que foi uma das coisas que foi falha no curso, não era algo que era muito incentivado não. Eu não lembro da gente trabalhar muito dentro dessa linha de investigação, de pesquisa não sabe? (Pedagogo 5)

Nem teve e assim, não me incentivava muito não essa pesquisa, você ir a campo, você buscar, você ter informaçôes. A pesquisa que se fala é campo, a pesquisa deles é só livro, estudo de casos, tudo nos livros, tudo nos livros, livro, livro, livro, trabalho em cima de trabalho e trabalho. Você fazer, construir, nada. (Pedagogo 13)

Lüdke (2012) ressaltou que tanto a prática quanto a formação para a pesquisa não têm sido consideradas relevantes pelos professores formadores que atuam nos cursos de Magistério e nas licenciaturas. Na concepção de Scheibe e Aguiar (1999), a formação profissional deve estar vinculada à pesquisa. Pimenta e Lima (2012), por sua vez, questionam como os professores poderão aprender a pesquisar se a pesquisa está ausente de sua formação? $\mathrm{O}$ estudo revelou que faltou estimular a prática investigativa, fato que pode estar vinculado ao locus formativo, o que já foi discutido ao tratamos do perfil dos sujeitos.

Os resultados obtidos nessa investigação se aproximam daqueles encontrados por Luz (2010, p.132), a qual afirma que "mesmo estando presente nos documentos, a pesquisa ainda continua a ser tratada como secundária na formação do pedagogo.” Nesse estudo, em que foi evidenciada uma ínfima presença da pesquisa na formação dos pedagogos, notamos uma contradição, pois um dos dispositivos que corroborou para as alteraçôes propostas no curso e que deu origem ao Parecer CFE no 252/69 foi a Lei no 5540/68, a qual dispunha, no seu artigo $2^{\circ}$, que "o ensino superior, indissociável da pesquisa, será ministrado em universidades e, excepcionalmente, em estabelecimentos isolados, organizados como instituiçôes de direito público ou privado." (BRASIL, 1968) Mediante o exposto, como justificar a ausência da pesquisa constatada na formação dos pedagogos que foram entrevistados?

Como pontos fortes do curso foram citados: a experiência daqueles que tinham cursado o Magistério e, por isso, possuíam uma base forma- 
tiva; a presença dos colegas que já atuavam, pois essa contribuía para fomentar o debate acerca das questóes teóricas; realizar o estágio no início do curso e a obrigatoriedade de cursá-lo mesmo já sendo docente; a formação universitária dos professores; as habilitações e ter estudado Língua Portuguesa em todos os períodos. A experiência dos colegas foi o aspecto mais citado pelos entrevistados:

E a minha turma era interessante porque ela era uma turma bem mista. Eu tinha colegas de sessenta anos, que já estavam quase aposentando como professoras e eu estava assim, começando a dar aulas. [...] Então a gente podia fazer muitas trocas. Tinha pessoas que já trabalhavam assim como tinham pessoas mais novas, como eu, mas foi uma riqueza muito grande. Essa troca com pessoas já experientes, que já tinham a experiência de professor e estavam ali cursando Pedagogia. (Pedagogo 2)

Para Imbernón (2009, p. 64), “o compartilhar dúvidas, contradiçôes, problemas, sucessos e fracassos são elementos importantes na formação das pessoas e de seu desenvolvimento pessoal e profissional."

Como lacunas, eles destacaram o fato de o curso ter sido muito teórico, sendo que a teoria deveria ter sido mais articulada com a prática. Essa falta de articulação entre teoria e prática gerou dificuldades para alguns profissionais quando partiram para sua atuação profissional, o que também foi explicitado por Luz (2010). Os estudos acerca da formação de professores têm apresentado, em suas análises, o favorecimento da teoria em detrimento da prática, segundo apontam Pimenta (1997), Gatti e Barretto (2009), Cruz (2011). Para Saviani (2007, p.108),

a prática é a razão de ser da teoria, o que significa que a teoria só se constituiu e se desenvolveu em função da prática que opera, ao mesmo tempo, como seu fundamento, finalidade e critério de verdade. A teoria depende, pois, radicalmente da prática. Os problemas de que ela trata são postos pela prática e ela só faz sentido enquanto é acionada pelo homem como tentativa de resolver os problemas postos pela prática. Cabe a ela esclarecer a prática, tornando-a coerente, consistente, conseqüente e eficaz. 
Portanto, a prática igualmente depende da teoria, já que sua consistência é determinada pela teoria. Assim, sem a teoria a prática resulta cega, tateante, perdendo sua característica específica de atividade humana.

Ao focarmos nosso olhar para a formação inicial, consideramos que, para esses profissionais, predominou um enfoque mais teórico do conhecimento, com pouca inserçáo no cotidiano da escola básica, seja nos estágios ou nos projetos de extensão, e poucos tiveram a oportunidade de participar da pesquisa. Também identificamos aspectos que têm sido recorrentes em investigaçóes que tratam da formaçáo do pedagogo, como a necessidade de se alcançar maior equilíbrio entre teoria e prática, carga horária insuficiente para determinados conteúdos e para o estágio.

Outras lacunas como o grande número de disciplinas do curso, a necessidade de se aprofundar mais em alguns conteúdos, a infraestrutura, o pouco apoio dado à pesquisa, a falta de oferta para participar de atividades de extensão e a oferta do estágio apenas ao fim do curso também foram evidenciadas.

\section{Como ocorre a formação continuada dos pedagogos?}

A LDB no 9394/96 contribuiu para o investimento na formação inicial ao tornar obrigatório o nível superior para os docentes que atuam na Educação Básica. Em relação à formação continuada, no artigo 67 dessa lei é outorgada ao poder público das três esferas a responsabilidade pela promoção da valorização dos profissionais da educação, inclusive, como obrigação, o aperfeiçoamento profissional continuado. A formação continuada na concepçáo de Gatti (2008, p. 57),

ora se restringe o significado da expressão aos limites de cursos estruturados e formalizados oferecidos após a graduação, ou após ingresso no exercício do magistério, ora ele é tomado de modo amplo e genérico, como compreendendo qualquer tipo de atividade que venha a contribuir para o desempenho profissional - horas de trabalho coletivo na escola, reunióes peda- 
gógicas, trocas cotidianas com os pares, participação na gestão escolar, congressos, seminários, cursos de diversas naturezas e formatos, oferecidos pelas Secretarias de Educação ou outras instituiçôes para pessoal em exercício nos sistemas de ensino, relaçôes profissionais virtuais, processos diversos a distância (vídeo ou teleconferências, cursos via internet etc.), grupos de sensibilização profissional, enfim, tudo que possa oferecer ocasião de informação, reflexão, discussão e trocas que favoreçam o aprimoramento profissional, em qualquer de seus ângulos, em qualquer situação.

Discute-se, hoje, a necessidade de superar os antigos modelos de formaçáo e de se considerar o protagonismo dos professores ao propiciar as ações de formação. Para Gatti e Barretto, (2009, p.231), “[...] os processos de formação continuada que buscam modificar conceitos, atitudes e práticas não podem ignorar o que pensam e sabem os professores e as influências do ambiente sociocultural em que vivem e trabalham." Ao tratar da formação continuada, dos relatos dos pedagogos emergem questóes alusivas à importância dessa formação e como eles têm se formado no exercício da profissão. Eles atribuem à educação continuada um sentido de aprimoramento profissional que busca acompanhar os avanços e renovaçóes da área em que atuam. Segundo os profissionais, a formação continuada se torna relevante por dar prosseguimento à formação de base iniciada no curso de graduação:

A formação continuada é importantíssima, que vai de encontro ao que eu estava falando, porque ele [o pedagogo] tem que se atualizar constantemente. Porque sempre surgem coisas novas. Todo mundo está aprendendo coisas novas a cada dia, não só na área que eu atuo, mas, por exemplo, ontem eu estava participando de um grupo de estudo sobre gêneros textuais e instâncias discursivas. Isso me ajuda na hora que eu vou ajudar o professor de Português, a pensar no que ele vai trazer para a sala de aula, como que ele vai atuar. Entáo, o pedagogo também tem que ter esses conhecimentos de outras áreas. Não é a área dele, mas que ele precisa dar suporte nessas áreas. Entấo eu acho 
que a formação continuada ela é essencial, porque a formação inicial, ela não dá conta, sozinha, é, de todas essas demandas que existem aí. [...] Então tem que estar mesmo constantemente se atualizando. E aí a formação continuada é fundamental. (Pedagogo 4)

Os entrevistados se formam participando de cursos, eventos, lendo, pesquisando, trocando ideias e experiências com outros profissionais, como relata o Pedagogo 2: "Então, um constante estudo mesmo, esse estudo não só acadêmico, mas autônomo, você ler bastante, buscar, pesquisar, trocar ideias com outras pessoas, buscar informações da prática de outras pessoas [...]" Alguns têm investido na formação por meio de cursos de curta duração, de especialização e disciplinas isoladas de Mestrado. Apenas um profissional citou que há uma prática de encontro mensal com os profissionais na rede em que atua, mas esses encontros não são realizados exclusivamente para propiciar a formação continuada, já que também têm a finalidade de repassar informações de secretarias e outros órgãos. "Então, mensalmente nós nos encontramos para informações que elas às vezes precisam ter e que vem da Superintendência Regional de Ensino, que vem da própria Secretaria de Educação, que vem de outras Secretarias [...]" (Pedagogo 2) Outro profissional mencionou a existência de um programa de formação continuada institucionalizado na sua rede, contando, inclusive, com uma consultoria. Esse programa atende aos pedagogos, diretores e vice-diretores.

Os dados coletados indicaram que tanto na rede estadual quanto na municipal, há a oferta de formaçôes a partir de parcerias firmadas com a Universidade Federal de Ouro Preto e órgãos do governo estadual e federal, todavia, nenhum dos entrevistados mencionou algum curso ou ação diretamente voltado para o pedagogo, confirmando a existência de uma lacuna na formaçáo continuada desses profissionais. O mesmo cenário em que se evidencia a relevância da formação continuada também apresenta uma contradição, pois, apesar de haver um crescimento na oferta de açôes de formação voltadas para os docentes, inexistem propostas específicas para o pedagogo, como se apenas os professores demandassem essa formação. Esses achados nos remetem a três questôes: a inexistência dessa 
formação específica; a forma como esses profissionais têm desenvolvido sua formação continuada; a responsabilidade por essa oferta.

A inexistência de uma formação específica para esse profissional reitera que "a formação continuada é organizada com pouca sintonia com as necessidades dos professores e da escola” (GATTI; BARRETO, 2009, p.221) e que para os pedagogos que se encontram no exercício da coordenação pedagógica são oferecidos cursos que tratam "da docência e prática dos professores, sendo raros os que oferecem formação específica para este profissional [...]" (PLACCO; SOUZA; ALMEIDA, 2012, p.9) Como na maioria das vezes não há um programa de formação continuada voltado especificamente para os pedagogos, eles participam das açóes voltadas aos professores, como o Pacto Nacional pela Alfabetização na Idade Certa (PNAIC), programa do governo federal (BRASIL, 2012) e o Programa de Intervenção Pedagógica (PIP) (MINAS GERAIS, 2013). Ao buscarem estratégias próprias de formação continuada, os profissionais demonstram autonomia e responsabilidade na busca dessa formação e se distanciam do modelo da formação hegemônica que predominou há algum tempo quando as formas de capacitação se davam pela participação em cursos cujo participante era um mero receptor de conteúdos, a teoria era privilegiada em detrimento da prática e do contexto do participante.

Não obstante, essa falta de formação específica sinaliza que o poder público da região não tem envidado esforços suficientes para garantir a formação continuada de todos os profissionais da educação, conforme estabelece a LDB no 9394/96. Comprova ainda que não há, por parte dos órgáos gestores da regiáo pesquisada, uma preocupação em realizar um diagnóstico das necessidades formativas dos pedagogos, planejando e estabelecendo junto com eles uma agenda de formação que se paute pelas suas reais necessidades e que atenda aos seus interesses, o que é fundamental na visão de Imbernón (2009) e de Pimenta e Lima (2012), já que professor e pedagogo não são meros executores tal como foi concebido pelo modelo da racionalidade técnica. As demandas e as vozes desses sujeitos precisam ser consideradas, pois, conforme afirmam Pimenta e Lima (2012), a escola é o ponto de chegada e de partida das açóes de formação continuada e, como declara Imbernón (2009), não se separa a formação do seu contexto de trabalho. 


\section{Consideraçóes Finais}

A partir da investigação desenvolvida, obtivemos as respostas para os objetivos que foram estabelecidos, o que possibilitou responder à questáo central do estudo. A discussão acerca do curso de Pedagogia e da formação do pedagogo demonstrou as mudanças e alguns desafios ainda presentes no processo formativo desses profissionais. Ao investigarmos quem são os pedagogos que atuam nas instituiçôes de ensino público da SRE-OP identificamos que eles são os Especialistas de Educação formados na vigência do Parecer CFE 252/69, quando o curso de Pedagogia estava estruturado por habilitaçôes. Esses profissionais, em sua maioria, têm na gênese de sua formação o curso de Magistério e a formação que receberam foi embasada nos princípios da racionalidade técnica, eficiência e produtividade. Como apenas um homem participou da pesquisa, os achados reafirmaram a preponderância do sexo feminino no Magistério.

Embora a formação profissional não possa ser desvinculada da pesquisa, na formação que os entrevistados receberam a pesquisa foi secundarizada, o que pode estar associado ao locus de formação. Nos depoimentos dos sujeitos da pesquisa, fica evidente que o curso foi considerado muito teórico, o que pode ser explicado em função das metodologias mais utilizadas pelos professores, com o predomínio de aulas expositivas. O contato com a Educação Básica se deu mais a partir do estágio, evidenciando a necessidade de se propiciar outras formas de inserção no campo profissional. A maioria realizou o estágio na sua área de habilitação, mas apenas dois o fizeram no início do curso, explicitando que houve uma prática de se realizar o estágio ao final do curso.

$\mathrm{Na}$ análise da formação continuada nos chamou a atenção o fato de não haver uma formação específica para os pedagogos no exercício da função, embora essa formação esteja prevista em lei (BRASIL, 1996). Os profissionais têm se formado de forma autônoma ou a partir das formaçóes propostas para os docentes. A ausência de uma formaçáo específica pode comprometer o desempenho do profissional pela falta de discussão acerca das especificidades do campo pedagógico e por não considerar o protagonismo, o contexto e o que pensam e sabem os pedagogos, além de demonstrar o descumprimento da legislação. Esses resultados nos levam a refletir sobre as estratégias utilizadas pelas secretarias de educação encarregadas 
da formulação e da implementação das políticas de formação continuada e também sobre como podemos fortalecer o compromisso da universidade "com o acompanhamento, apoio e atualização contínuos dos profissionais docentes que elas formam [...]" (GATTI; BARRETTO, 2009, p.225), para tentar reverter o cenário apresentado e promover a crítica e a autonomia dos pedagogos embasadas no processo de ação-reflexáo-ação.

Sem fazer distinção entre o profissional que exerce sua atividade dentro ou fora da sala de aula, mas considerando seu locus de atuação que é a escola e o lugar que ele ocupa no discurso educacional buscamos, nesta pesquisa, privilegiar a voz desses sujeitos para falarem de si, de sua formação e de seu contexto de trabalho. Gestores e políticos podem até ignorar as vozes dos educadores, mas de forma alguma podem alegar a inexistência de uma produção que expressa a realidade à qual estão subjugados os professores brasileiros.

Finalizando, reiteramos a necessidade de avaliar constantemente a formação oferecida no curso de Pedagogia, não só devido às alteraçôes pelas quais ele passou, mas também pelo lugar que ele ocupa no cenário das políticas públicas brasileiras; e ainda, em decorrência do resultado de pesquisas como essas que, ao desvelarem os processos formativos dos pedagogos, expôem as lacunas e limitaçóes presentes na formação inicial e continuada.

Julgamos que para as instituiçóes formadoras esta pesquisa é relevante por tomar conhecimento dos pontos fortes do curso e daqueles que necessitam ser aprimorados visando alcançar uma formação mais abrangente e, consequentemente, uma melhor qualificação dos egressos. Por fim, reafirmamos que o curso de Pedagogia permanece no cerne dos debates do meio educacional e essa condição, por enquanto, não se modificará, pois as discussóes em torno da formaçáo ofertada estão longe de serem encerradas. Permanecemos entre velhas e novas questóes.

\section{Notas}

1 As Superintendências Regionais de Ensino (SRE), segundo a Secretaria de Educação de MG, têm por objetivo exercer, em nível regional, as açōes de supervisão técnica, orientação normativa, cooperação e de articulação e integração Estado e Município em consonância com as políticas educacionais. Municípios que compóe a SRE-OP: Acaiaca, Diogo de Vasconcelos, Itabirito, Mariana e Ouro Preto.

2 Embora a amostra seja constituída por sujeitos do sexo feminino e masculino, ao apresentarmos os dados, trataremos os entrevistados por pedagogos. 


\section{Referências}

ALBUQUERQUE, H. M. de P.; HAAS, C. M.; ARAÚJO, R. M. B. de. Formação de professores da educação básica no Brasil - Curso de Pedagogia - Licenciatura, em instituições da Região Sudeste. Acta Scientiarum Education, Maringá, UEM, v. 35, n. 1, p. 105-115, jan./jun., 2013. Disponível em: http://periodicos.uem.br/ojs/index.php/ ActaSciEduc/article/view/16504. Acesso em: 29 nov. 2014.

BARDIN, L. Análise de Conteúdo. São Paulo: Edições 70, 2011.

SILVA, C. S. da Curso de pedagogia no Brasil - história e identidade. Campinas: Autores Associados, 2006.

. Curso de Pedagogia no Brasil: uma questão em aberto. In: PIMENTA, Selma Garrido (Org.) Pedagogia e Pedagogos: caminhos e perspectivas. São Paulo: Cortez, 2011. p. 131-154.

BOGDAN, R.; BIKLEN, S. Investigação Qualitativa em Educação - uma introdução à teoria e aos métodos. Porto: Porto Editora, 1994.

BRASIL. Conselho Federal de Educação. Parecer n 251/62. Fixa o currículo mínimo e a duração do Curso de Pedagogia. Relator: Valnir Chagas. In: Documenta, n. 11, p.59-66, jan./fev., 1963.

. Conselho Federal de Educação. Parecer n 252/69. Fixa os mínimos de conteúdo e duração a serem observados na organização do curso de Pedagogia. Relator: Valnir Chagas. In: Documenta, n. 100, p. 101-139, abr., 1969.

. Conselho Federal de Educação. Parecer n 292/62. Fixa a parte pedagógica dos currículos mínimos relativos aos cursos de licenciatura. In: Documenta, n. 10, p. 95-101, dez., 1962.

. Conselho Nacional de Educação. Resolução no 1/2006 de 15 de maio de 2006. Institui Diretrizes Curriculares Nacionais para o Curso de Graduação em Pedagogia, licenciatura. Diário Oficial da União, Brasília, 16 maio 2006, Seção 1, p. 11. Disponível em: http://portal.mec.gov.br/cne/arquivos/pdf/rcp01_06.pdf. Acesso em: 21 dez. 2013.

. Decreto no 7.219 de 24 de junho de 2010. Dispóe sobre o Programa Institucional de Bolsa de Iniciação à Docência - PIBID e dá outras providências. Diário Oficial da União, Brasília, 25 jun. 2010. Disponível em: http://www2.camara. leg.br/legin/fed/decret/2010/decreto-7219-24-junho-2010-06872publica caooriginal127693-pe.html. Acesso em: 11 jul. 2015.

Decreto-Lei no 1190 de 04 de abril de 1939. Dá organização à Faculdade Nacional de Filosofia. Diário Oficial da União, Rio de Janeiro, RJ, 06 abr. 1939. Disponível em: http:/www2.camara.leg.br/legin/fed/declei/1930-1939/decreto-lei1190-4-abril-1939-49241-publicacaooriginal-1-pe.html. Acesso em: 08 set. 2013. 
Lei no 5.540 , de 28 de novembro de 1968. Fixa normas de organização e funcionamento de ensino superior e sua articulaçáo com a escola média e dá outras providências. Diário Oficial da União, Brasília, 29 nov. 1968. Disponível em: http:// www2.camara.leg.br/legin/fed/lei/1960-1969/lei-5540-28-novembro-1968-359201norma-pl.html. Acesso em: 23 dez. 2013.

. Lei no 5.692, de 11 de agosto de 1971. Fixa diretrizes e bases para o ensino de $1^{\circ}$ e $2^{\circ}$ graus, e dá outras providências. Diário Oficial da União, Brasília, 12 ago. 1971. Disponível em: http://www2.camara.leg.br/legin/fed/lei/1970-1979/lei-5692-11-agosto1971-357752-publicacaooriginal-1-pl.html. Acesso em: 23 dez. 2013.

. Lei n. 9.394, de 20 de dezembro de 1996. Dispóe sobre as Diretrizes e Bases da Educação Nacional. Diário Oficial da União, Brasília, DF, 23 dez. 1996. Disponível em: < http://www2.camara.leg.br/legin/fed/lei/1996/lei-9394-20-dezembro-1996362578-publicacaooriginal-1-pl.html. Acesso em: 23 dez. 2013.

. Ministério da Educação e Cultura. Portaria no 867/12. Brasília, 2012. Institui o Pacto Nacional pela Alfabetização na Idade Certa e as ações do Pacto e define suas diretrizes gerais. Disponível em: http://pacto.mec.gov.br/documentos-importantes. Acesso em: 13 jul. 2015.

BRAÚNA, R. de C. de A. A construção de identidades profissionais de estudantes de Pedagogia. In: Reunião Nacional da Associação Nacional de Pós-Graduação e Pesquisa em Educação, XXXII, 2009, Caxambu. Disponível em: http://32reuniao.anped.org.br/ arquivos/posteres/GT08-5280--Int.pdf. Acesso em: 06 jul. 2015.

CARVALHO, M. P. de. Trabalho docente e relaçóes de gênero: algumas indagaçóes. Revista Brasileira de Educação, Rio de Janeiro, n. 2, p. 77-84, maio/jun/jul. 1996. Disponível em: http://anped.org.br/rbe/rbedigital/RBDE02/RBDE02_08_MARILIA_ PINTO_DE_CARVALHO.pdf. Acesso em: 06 jul. 2015.

COMENIUS, J. A. Didática Magna. Aparelho Crítico Marta Fattori; Tradução de Ivone Castilho Beneditti. 4 ed. São Paulo: Martins Fontes, 2011.

CRUZ, G. B. da. 70 anos do curso de Pedagogia no Brasil: uma análise a partir da visão de dezessete pedagogos primordiais. Educação \& Sociedade, Campinas, v. 30, n. 109, p. 1187-1205, set./dez. 2009.Disponível em: http://www.scielo.br/pdf/es/v30n109/ v30n109a13.pdf>.Acesso em: 27 mar. 2014.

. Curso de Pedagogia no Brasil: história e formação com pedagogos primordiais. Rio de Janeiro: Wak Editora, 2011.

. Teoria e prática no curso de pedagogia. Educação e Pesquisa, São Paulo, v. 38, n. 1, p.149-164, 2012. Disponível em: http://www.scielo.br/pdf/ep/v38n1/aop230.pdf. Acesso em: 16 dez. 2014.

DINIZ-PEREIRA, J. E. As licenciaturas e as novas políticas educacionais para a formação docente. Educação \& Sociedade, ano XX, n. 68, p. 109-125, dez. 1999. Disponível em: http://www.scielo.br/pdf/es/v20n68/a06v2068. Acesso em: 11 jul. 2013. 
EVANGELISTA, O.; TRICHES, J. Diretrizes curriculares nacionais para o curso de pedagogia: docência, gestão e pesquisa. In: Seminário de Pesquisa em Educação da Região Sul, VII. Itajaí: 2008. P. 1-17. Disponível em: http://www.portalanpedsul.com.br/ admin/uploads/2008/Politicas_publicas_e_Gestao_educacional/Trabalho/07_22_29_ DIRETR 1.PDF. Acesso em: 07 out. 2014.

FRANCO, M. A. S.; LIBÂNEO, J. C.; PIMENTA, S. G. As dimensóes constitutivas da Pedagogia como campo de conhecimento. Educação em Foco, v. 14, n. 17, p. 55-78, jul. 2011. Disponível em: http:/www.uemg.br/openjournal/index.php/ educacaoemfoco/article/view/103/138. Acesso em: 21 jun. 2014.

GATTI, B. A. A formação inicial de professores para a educação básica: as licenciaturas. Revista USP, São Paulo, n. 100, p. 33-46, dez./jan./fev. 2013-2014. Disponível em: http://www.revistas.usp.br/revusp/article/view/76164. Acesso em: 03 mar. 2015.

- Análise das políticas públicas para formação continuada no Brasil, na última década. Revista Brasileira de Educação, Rio de Janeiro, v. 13, n. 37, p. 57-70, jan./abr. 2008. Disponível em: http://www.scielo.br/pdf/rbedu/v13n37/06.pdf. Acesso em: 19 jul. 2014.

(Coord.); BARRETTO, E. S. de S. Professores do Brasil: impasses e desafios. Brasília: UNESCO, 2009. Disponível em: http://unesdoc.unesco.org/ images/0018/001846/184682por.pdf. Acesso em: 07 jun. 2013.

IMBERNÓN, F. Formação permanente do professorado: novas tendências. São Paulo: Cortez, 2009. Olhar de professor, Ponta Grossa, v. 10, p.11-33, 2007. Disponível em http://www.uepg. br/olhardeprofessor. Acesso em: 14 fev. 2015.

Ainda as perguntas: o que é pedagogia, quem é o pedagogo, o que deve ser o curso de Pedagogia. In: PIMENTA, S. G. (Org.). Pedagogia e Pedagogos: caminhos e perspectivas. São Paulo: Cortez, 2011. p. 63-100.

Pedagogia e Pedagogos: inquietaçóes e buscas. Educar. Curitiba: Editora da UFPR, n. 17, p. 153-176. 2001. Disponível em: http://www.scielo.br/pdf/er/n17/n17a12. pdf. Acesso em: 09 out. 2011.

. Pedagogia e pedagogos, para que? São Paulo: Cortez, 2010.

; PIMENTA, S. G. Formação de profissionais da educação: visão crítica e perspectiva de mudança. In: PIMENTA, Selma Garrido (Org.). Pedagogia e Pedagogos: caminhos e perspectivas. São Paulo: Cortez, 2011. p. 15-61.

LEITE, Y. U. F.; LIMA, V. M. M. Cursos de Pedagogia no Brasil: o que dizem os dados do INEP/MEC? Ensino Em-Revista, Uberlândia, v.17, n.1, p. 69-93, jan./ jun. 2010. Disponível em: http://www.seer.ufu.br/index.php/emrevista/article/ view/8185/5197. Acesso em: 03 mar. 2015. 
LIMA, E. de F. Formação de professores - passado, presente e futuro: o curso de Pedagogia. In: MACIEL, L. S. B.; Shigunov Neto, A. (Orgs). Formação de Professores Passado, Presente e Futuro. São Paulo: Cortez, 2004. p.15-34.

LUDKE, M. A complexa relaçáo entre o professor e a pesquisa. In: ANDRÉ, M. E. D. A. de (Org.). O papel da pesquisa na formação e na prática dos professores. Campinas: Papirus, 2012. p. 27-54.

LUZ, T. H. B. e S. Ser Pedagogo: o conhecimento da identidade profissional pelas histórias de vida. 2010. 166 f. Dissertação (Mestrado em Educação) - Programa de Pós-Graduação em Educação, Universidade Federal do Piauí, Piauí, 2010.

MARIN, A. J. O curso de Pedagogia em foco: fragilidades constantes e urgências da formação. In: Encontro Nacional de Didática e Prática de Ensino, XVII. Fortaleza: 2014. Disponível em: http://www.uece.br/eventos/xviiendipe/. Acesso em: 24 jan. 2015.

MINAS GERAIS. Secretaria de Estado de Educação. Guia de Revisão e Reorganização do Plano de Intervenção Pedagógica. 2013. Disponível em: https://www.educacao. mg.gov.br/images/stories/pip/CARTILHApip/CARTILHA_PIP_GUIA_REVISAO_ WEB.pdf. Acesso em: 13 jul. 2015.

NUNES, C. M. F.; ARAÚJO, R. M. B. de. A Formação para Gestão no Curso de Pedagogia: O Projeto Pedagógico e a Formação do Pedagogo na Percepçáo dos/ as Alunos/as. In: RAHME, M. M. F.; FRANCO, M. A. M.; DULCI, L. C. (Org.). Formação e politicas públicas na educação: tecnologia, aprendizagem, diversidade e inclusão. Jundiaí: Paco Editorial, 2014, p. 68-85.

PIMENTA, S. G. A formação de professores para a Educaçáo Infantil e para os anos iniciais do Ensino Fundamental: análise do currículo dos cursos de Pedagogia de instituiçōes públicas e privadas do Estado de São Paulo. In: Encontro Nacional de Didática e Prática de Ensino, XVII. Fortaleza: 2014. Disponível em: http://www.uece. br/eventos/xviiendipe/. Acesso em: 24 jan. 2015.

- O estágio na formação de professores: unidade teoria e prática? Sáo Paulo:

Cortez, 1997.

.; LIMA, M. S. L. Estágio e Docência. São Paulo: Cortez, 2012.

PINHEIRO, G. C. G.; ROMANOWSKI, J. P. Curso de Pedagogia: formação do professor da Educaçáo Infantil e dos anos séries iniciais do Ensino Fundamental. Formação Docente, Belo Horizonte, v. 2, n. 3, p. 136-151, ago./dez. 2010. Disponível em: http://formacaodocente.autenticaeditora.com.br/artigo/exibir/8/24/1> Acesso em: 03 mar. 2015.

PLACCO, V. M. N. de S.; SARMENTO, M. L. de M. Outro jeito de dar aulas: Orientação de Estudos. In: BRUNO, E. B. G.; CHRISTOV, L. H. da S. (Org.). O Coordenador Pedagógico e a Educação continuada. São Paulo: Edições Loyola, 2009. p. 41-50. 
.; SOUZA, V. L. T. de; ALMEIDA, L. R. de. Proposição de Políticas Públicas quanto à formação de Coordenadores Pedagógicos, Formadores de Professores. In: Encontro Nacional de Didática e Prática de Ensino, XVI. Campinas: 2012. Disponível em: http://www.infoteca.inf.br/endipe/smarty/templates/arquivos_template/ upload_arquivos/acervo/docs/0057s.pdf. Acesso em: 30 abr. 2014.

SAVIANI, D. Pedagogia: o espaço da educação na universidade. Cadernos de Pesquisa. São Paulo, v. 37, n. 130, p. 99-134, jan./abr. 2007. Disponível em: http://www.scielo.br/ pdf/cp/v37n130/06.pdf. Acesso em: 29 nov. 2014.

. Formação de Professores: aspectos históricos e teóricos do problema no contexto brasileiro. Revista Brasileira de Educação, v. 14, n. 40, jan./abr. 2009. Disponível em: http:/www.scielo.br/pdf/rbedu/v14n40/v14n40a12.pdf. Acesso em: 11 jun. 2014.

. História da Formação docente no Brasil: três momentos decisivos. Educação. Revista do Centro de Educação, v. 30, n. 2, julio-diciembre, p.11-26, 2005. Disponível em: http://www.redalyc.org/articulo.oa?id=117120356002. Acesso em: 11 jun. 2014.

SCHEIBE, L.; AGUIAR, M. Â. Formação de profissionais da educação no Brasil: o curso de pedagogia em questão. Educação \& Sociedade, Campinas, v. 68, p. 220-238, dez. 1999. Disponível em: http://www.scielo.br/pdf/es/v20n68/a12v2068.pdf. Acesso em: 13 out. 2011.

.; DURLI, Z. Curso de Pedagogia no Brasil: olhando o passado,

compreendendo o presente. Educação em Foco. Belo Horizonte, v. 14, n. 17, p.

79-109, jul. 2011. Disponível em: < http://www.uemg.br/openjournal/index.php/ educacaoemfoco/article/view/104. Acesso em: 03 mar. 2015.

SOMACAL, C. M. Professor Pedagogo: que profissional é este? 2010. 177 f. Dissertação (Mestrado em Educação) Universidade Federal de Santa Catarina, Florianópolis, 2010. Disponível em: https://repositorio.ufsc.br/xmlui/handle/123456789/94585. Acesso em: 01 dez. 2014.

UNESCO. O Perfil dos professores brasileiros: o que fazem, o que pensam, o que almejam... / Pesquisa Nacional UNESCO, São Paulo: Moderna, 2004. Disponível em: http://unesdoc.unesco.org/images/0013/001349/134925por.pdf. Acesso em: $01 \mathrm{dez}$ 2014.

Recebido em I2 dez. 2017 / Aprovado em Is fev. 2019 Para referenciar este texto:

LUCINDO, N. I.; ARAÚJO, R. M. B. Quem são os Pedagogos que atuam nas instituiçóes de ensino público da SRE de Ouro Preto, Minas Gerais? O perfil e a formação em foco. EccoS - Revista Científica, São Paulo, n. 49, p. I-30, e8I64, abr./ jun. 2019. Disponível em: https://doi.org/I0.5585/EccoS.n49.8164>. 